\title{
Erratum to: Sequential metalation of benzene: electronic, bonding, magnetotropic and spectroscopic properties of coinage metalated benzenes studied by DFT
}

\author{
Athanassios C. Tsipis ${ }^{1}$ - Dimitrios N. Gkarbounis ${ }^{1}$
}

Published online: 12 June 2015

(C) Springer-Verlag Berlin Heidelberg 2015

Erratum to: J Mol Model (2015) 21:153

DOI 10.1007/s00894-015-2661-x

The original version of this article unfortunately contained a mistake. Scheme 3 was incorrect. The correct version of Scheme 3 is given below.
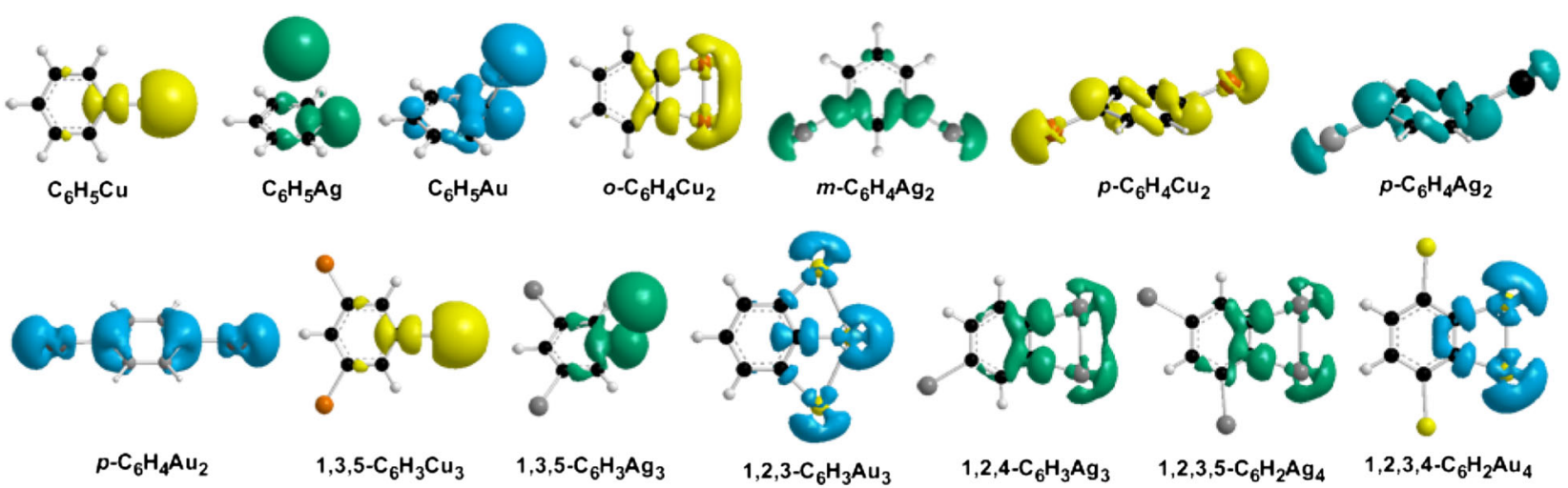

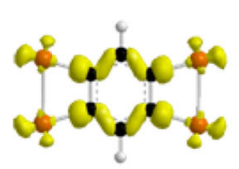

$1,2,4,5-\mathrm{C}_{6} \mathrm{H}_{2} \mathrm{Cu}_{4}$

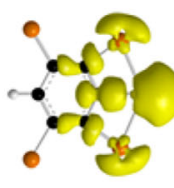

$\mathrm{C}_{6} \mathrm{HCu}_{5}$

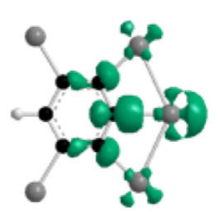

$\mathrm{C}_{6} \mathrm{HAg}_{5}$

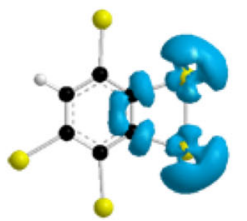

$\mathrm{C}_{6} \mathrm{HAu}_{5}$
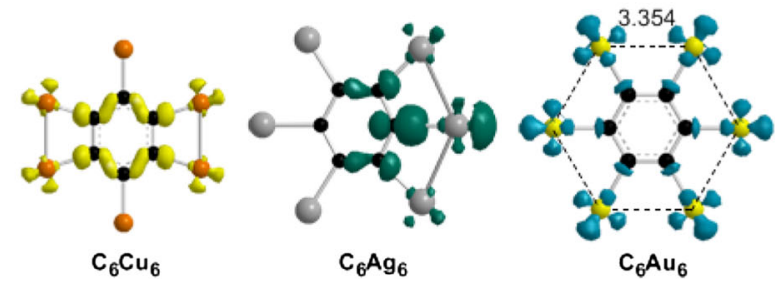

Scheme $33 \mathrm{D}$ plots of the spin densities (isospin surface=0.005) in the triplet excited states of representative $\mathrm{C}_{6} \mathrm{H}_{6-\mathrm{n}} \mathrm{M}_{\mathrm{n}}(\mathrm{M}=\mathrm{Cu}, \mathrm{Ag}, \mathrm{Au} ; n=1-6) \mathrm{molecules}$

The online version of the original article can be found at http://dx.doi.org/ 10.1007/s00894-015-2661-x.

\section{Athanassios C. Tsipis}

attsipis@uoi.gr

Department of Chemistry, Tsipis Laboratory of Inorganic and

General Chemistry, University of Ioannina, Ioannina 45110, Greece 